\title{
Comparative Analysis of the Success Rate with the use of Fibrin Sealant in Tympanoplasty
}

\author{
Rohan Bidaye $^{1 *}$, Edel Ann Abreo $^{2}$ and Kantilal Desarda ${ }^{3}$ \\ ${ }^{1}$ Consultant ENT surgeon, King Edward Memorial Hospital, India \\ ${ }^{2}$ Clinical Research student, Columbia University, United States \\ ${ }^{3}$ Head of Department ENT, King Edward Memorial Hospital, India
}

Submission: May 09, 2020; Published: May 26, 2020

*Corresponding author: Rohan Bidaye, Consultant ENT surgeon, King Edward Memorial Hospital, Rasta Peth, Pune, Maharashtra, India

\section{Abstract}

Objective: To test the hypothesis that a Fibrin sealant (FS) can improve the success rate of Tympanoplasty surgery, a prospective trial was undertaken. The aim was to compare the graft uptake and hearing outcomes in type 1- Tympanoplasty with the use of a Fibrin sealant to secure the graft.

Methods: A prospective study was performed on 80 patients within the age group of 18 to 64 years, from April 2014 to March 2016, at our institute. Otological examination and Audiometry findings were recorded with emphasis on the duration of symptoms, size of the perforation and the degree of hearing loss. Of the 80 patients undergoing type 1 Tympanoplasty with temporalis fascia graft, 40 patients (cases) underwent the surgery with the use of FS to secure the graft in place. The rest of the 40 patients (controls) served as a control group for this study. Statistical analysis was done using the Chi-square test.

Results: In the post-operative results, the graft uptake success rate in cases was $95.00 \%$, whereas the success rate in control group was $80.0 \%$. This difference was statistically significant (Chi. Square $=4.114, \mathrm{DF}=1, \mathrm{p}=0.043$ ). Hearing outcome showed a statistically significant difference with predominance of normal hearing in cases (95.00\%), whereas in the control group it was $77.50 \%$ (Chi. Square=6.155, DF=2,p=0.046).

Conclusion: The FS improves the success rate in terms of graft uptake and hearing outcome in type 1 tympanoplasty.

Keywords: Fibrin tissue adhesive; Tympanoplasty; Tissue grafts; Success rate

Abbreviations: FS: Fibrin Sealant; df: Degree of Freedom

\section{Introduction}

Type 1 Tympanoplasty is a surgical technique to repair a defect in the tympanic membrane alone, with the placement of a graft, either medial or lateral to the tympanic membrane annulus [1]. Over the years, various types of autologous grafts have been experimented with, with variable success rates. Shea in 1959 found that a vein could be used as a graft satisfactorily [2]. Then Hermann used the temporalis fascia as a graft in tympanoplasty in 1960. Successively Goodhill introduced the idea of grafting using tragal cartilage and perichondrium. Today, though the fascia temporalis is the most common graft adopted in tympanoplasty, newer studies have demonstrated that in terms of graft uptake and hearing outcome success rates, cartilage palisades are superior to temporalis fascia grafts with success rates of $75-80 \%$ [4-6]. Despite this, the failure rate using any of the above grafts or techniques is considerable, owing to graft displacement, postoperative bacterial infection and atrophy of middle ear mucosa etc., $[7,8]$. To reduce this failure rate FS has been used increasingly over the last few decades as a supplement to ontological procedures like tympanoplasty and stapedotomy.

The use of fibrin glue in otology procedures started in the 80 's with variable success rates, where some surgeons state that it is a physiological aid to the experienced skilful ear surgeon, yet not substantially interfering with the outcome of the operation.9 For example, Babighian G used the natural sealant Tissucol in oto-surgical and otoneurologic procedures, with success [9]. One laboratory study on pig's vocal cords supported the use of FS in vocal cord reconstruction as a means of increasing collagen deposition [10]. In a study on 53 patients, the authors noted 
a $98.1 \%$ success rate for closure of large perforations of the tympanic membrane [11]. The aim of our study was to compare and report the outcome in the terms of graft uptake and hearing outcomes after type 1- Tympanoplasty, with and without the use of a FS to secure the graft.

\section{Methods and Materials}

A prospective study was carried out from April 2014 to March 2016 for a duration of 2 years in the ENT department of King Edward Memorial Hospital, Pune, India. 80 patients satisfied the inclusion criteria for the trial. A Quasi-experimental study design was used, as it was difficult to obtain a surgical consent on blinding and randomization. Out of the 80 patients, 40 patients selected the intervention and were grouped as Cases, in which FS was used after type 1-Tympanoplasty while the other 40 patients served as Controls. Both groups were proven statistically comparable to minimize selection bias.

The patients selected for the study had unilateral chronic otitis media of the tubo-tympanic type with a central perforation. They had a conductive hearing loss of varying range. It was made sure that they had dry ear for at least 4 weeks prior to the procedure. Patients with active ear discharge, ossicular dysfunction, sensorineural hearing loss, attico-antral disease, complications of chronic suppurative otitis media or with any Sino-nasal, pathologies were excluded from the study. A detailed history regarding the duration of symptoms, nature of the disease, age and gender of the patient were noted. Otologic examination was performed noting the size of the perforation. Prior to the procedure, each patient underwent relevant ENT and medical investigations along with a Pure Tone Audiometry to quantify the hearing loss. The surgeries were performed by the same surgeon (Author 3) under general anesthesia, using the post auricular approach.

A Post auricular incision was made, and temporalis fascia graft harvested. Tympanotomy was performed and the perforation edges freshened. A tympano-meatal flap was raised and the ossicular status checked by the round window reflex. Temporalis fascia graft was placed by the underlay technique and the tympano-meatal flap repositioned back in place. The surgical steps were identical in both the groups until this step. In the cases, a thin layer of FS (around 0.5-1ml) was applied with the cannula and allowed to settle for 2 mins. This step of application of fibrin glue was not performed in the control group and instead dry gel foam pieces were used to secure the graft in place. The external ear canal was then packed with gel foam in both the groups followed by a mastoid dressing.

Postoperatively the patients were prescribed antibiotics and analgesics for 1 week. The dressing was changed at 48 hours and it was completely removed on the $7^{\text {th }}$ day. Eardrops were commenced on the $7^{\text {th }}$ day, which dissolved the gel foam. Follow up was done weekly for the first month and then fortnightly. The status of the neo-tympanum was recorded after the 4 th week and then at 2 months by Oto microscopy. Hearing assessment with pure-tone audiometry was repeated at 2 months after the surgery. The use of FS was then statistically analyzed by assessing the success of the graft uptake and the hearing outcome. Data analysis was done using Chi-squared test and degree of freedom (df) test on IBM-SPSS version 2.0.

\section{Results}

The patient's ages ranged from 18-64 years in both the groups, with mean Age in cases was 35.4 years while it was 33.53 years in the controls (Table 1 ). In the study over all, there was predominance of males $(57.50 \%)$, whereas females were $42.5 \%$, in both the groups (Table 2). The duration of the disease ranged from $2.5-7.5$ years. $16(40 \%)$ of the patients in the cases group and $14(35 \%)$ of the patients in the control group had the average range of duration of symptoms of 2-3 years (Table 3 ). The membrane perforation size was divided into small $\left(<15 \mathrm{~mm}^{2}\right)$ and large $\left(>15 \mathrm{~mm}^{2}\right)$. The controls had an equal number of small and large perforations (20 each) while the cases had 23 (57.5\%) small perforations while the rest. 17 (42.5\%) were large perforations (Table 4). On pure tone audiometry, the degree of hearing loss was divided into mild (26-40dB), moderate $(40-70 \mathrm{~dB})$, severe (70$90 \mathrm{~dB}$ ). Majority ( $57.5 \%$ in cases and $55 \%$ in controls) of subjects were noted to have mild hearing loss (Table 5).

Table 1: Age Distribution of Patients.

\begin{tabular}{|c|c|c|c|c|}
\hline \multirow{2}{*}{ Age in Years } & \multicolumn{2}{|c|}{ Cases } & \multicolumn{2}{c|}{ Controls } \\
\cline { 2 - 5 } & No. & \% & No. & $\%$ \\
\hline $18-27$ & 12 & 30 & 16 & 40 \\
\hline $28-37$ & 14 & 35 & 11 & 27.5 \\
\hline $38-47$ & 9 & 22.5 & 9 & 22.5 \\
\hline $48-57$ & 4 & 10 & 3 & 7.5 \\
\hline $58-64$ & 1 & 2.5 & 1 & 2.5 \\
\hline Total & 40 & 100 & 40 & 100 \\
\hline
\end{tabular}

(Total number) $\mathrm{n}=80$.

${ }^{*} p<0.05$ is statistically significant.

Mean $(\mathrm{m})$ age in Cases $=35.4$ years and Standard deviation (S.D) $=$ 10.9 years.

$\mathrm{m}$ age in Controls $=33.53$ years and S.D. $=11.06$.

Chi. Square $=1.074$,

Degree of freedom (Df) $=4$.

$p=0.898$ - statistically not significant.

Table 2: Gender Distribution of Patients.

\begin{tabular}{|c|c|c|c|c|}
\hline \multirow{2}{*}{ Gender } & \multicolumn{2}{|c|}{ Cases } & \multicolumn{2}{c|}{ Controls } \\
\cline { 2 - 5 } & No. & $\%$ & No. & $\%$ \\
\hline Male & 23 & 57.5 & 23 & 57.5 \\
\hline Female & 17 & 42.5 & 17 & 42.5 \\
\hline Total & 40 & 100 & 40 & 100 \\
\hline
\end{tabular}

$\mathrm{n}=80$.

${ }^{*} p<0.05$ is statistically significant.

Chi. Square $=0$.

$\mathrm{DF}=1$.

$p=1.000$ - statistically not significant. 


\section{Global Journal of Otolaryngology}

Table 3: Duration of Symptoms.

\begin{tabular}{|c|c|c|c|c|}
\hline \multirow{2}{*}{$\begin{array}{c}\text { Duration of Symptoms (in } \\
\text { years) }\end{array}$} & \multicolumn{2}{|c|}{ Cases } & \multicolumn{2}{c|}{ Controls } \\
\cline { 2 - 5 } & No. & $\%$ & No. & $\%$ \\
\hline $0.5-1.5$ & 10 & 25 & 12 & 30 \\
\hline $2-3$ & 16 & 40 & 14 & 35 \\
\hline $3.5-4.5$ & 7 & 17.5 & 9 & 22.5 \\
\hline $05-J u n$ & 6 & 15 & 3 & 7.5 \\
\hline $6.5-7.5$ & 1 & 2.5 & 2 & 5 \\
\hline Total & 40 & 100 & 40 & 100 \\
\hline
\end{tabular}

$\mathrm{n}=80$.

${ }^{*} p<0.05$ is statistically significant.

Chi. Square $=1.898$.

$\mathrm{Df}=4$.

$p=0.755$ - statistically not significant.

Table 4: Size of Perforation.

\begin{tabular}{|c|c|c|c|c|}
\hline \multirow{2}{*}{ Size of Perforation } & \multicolumn{2}{|c|}{ Cases } & \multicolumn{2}{c|}{ Controls } \\
\cline { 2 - 5 } & No. & $\%$ & No. & $\%$ \\
\hline Small & 23 & 57.5 & 20 & 50 \\
\hline Large & 17 & 42.5 & 20 & 50 \\
\hline Total & 40 & 100 & 40 & 100 \\
\hline
\end{tabular}

$\mathrm{n}=80$.

${ }^{*} p<0.05$ is statistically significant.

Chi. Square $=0.453$.

$\mathrm{Df}=1$.

$p=0.501-$ statistically not significant.
Table 5: Hearing profile before the surgery.

\begin{tabular}{|c|c|c|c|c|}
\hline \multirow{2}{*}{ Hearing Profile } & \multicolumn{2}{|c|}{ Cases } & \multicolumn{2}{c|}{ Controls } \\
\cline { 2 - 5 } & No. & $\%$ & No. & $\%$ \\
\hline Normal & 2 & 5 & 1 & 2.5 \\
\hline Mild & 23 & 57.5 & 22 & 55 \\
\hline Moderate & 15 & 37.5 & 17 & 42.5 \\
\hline Total & 40 & 100 & 40 & 100 \\
\hline
\end{tabular}

$\mathrm{n}=80$.

${ }^{*} p<0.05$ is statistically significant.

Chi. Square $=0.481$.

Df $=2$.

$p=0.786$ - statistically not significant.

Both cases and controls were matched adequately with no statistical difference noted between the gender distribution, duration of symptoms, size of perforation and the pre-operative hearing loss. The results were evaluated postoperatively in the form of graft uptake and hearing outcome. Postoperative and preoperative pure-tone audiograms were compared. Hearing and mean residual gaps were evaluated in speech frequencies of 500,1000 , and $2000 \mathrm{~Hz}$. An average hearing threshold of up to $25 \mathrm{~dB}$ over the three frequencies was considered Normal hearing. Postoperative results within the Normal hearing range were considered a successful hearing outcome.

The results regarding success rate of the graft uptake was recorded as $95 \%$ in the cases group vs $80 \%$ in the control (Table 6 ), while the cases group showed a $95 \%$ gain of normal/improved hearing and the control group just 77.5\% (Table 7) (Figure 1).
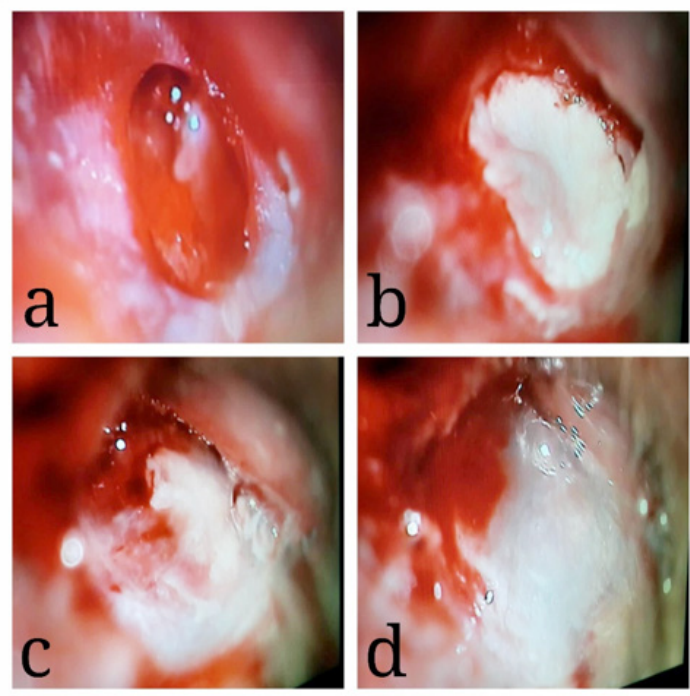

Figure 1: Fibrin sealant application over a Temporalis fascia graft.

a. Perforation with freshened margins.

b. Temporalis fascia graft in place.

c. Application of fibrin sealant over the graft.

d. Fibrin sealant forming a gel 2 minutes after application. 


\section{Global Journal of Otolaryngology}

Table 6: Post- operative Results (Success Rate).

\begin{tabular}{|c|c|c|c|c|}
\hline \multirow{2}{*}{ Success Rate } & \multicolumn{2}{|c|}{ Cases } & \multicolumn{2}{c|}{ Controls } \\
\cline { 2 - 5 } & No. & $\%$ & No. & $\%$ \\
\hline Successful & 38 & 95 & 32 & 80 \\
\hline Unsuccessful & 2 & 5 & 8 & 20 \\
\hline Total & 40 & 100 & 40 & 100 \\
\hline
\end{tabular}

$\mathrm{n}=80$.

${ }^{*} p<0.05$ is statistically significant.

Success rate in cases $-95.00 \%$.

Success rate in control group $-80.0 \%$.

Chi. Square $=4.114$

$\mathrm{Df}=1$.

$p=0.043-$ This difference was statistically significant.

Table 7: Post-operative Comparison of Hearing Outcomes.

\begin{tabular}{|c|c|c|c|c|}
\hline \multirow{2}{*}{ Hearing Outcomes } & \multicolumn{2}{|c|}{ Cases } & \multicolumn{2}{c|}{ Controls } \\
\cline { 2 - 5 } & No. & $\%$ & No. & $\%$ \\
\hline Mild Loss & 1 & 2.5 & 8 & 20 \\
\hline Moderate Loss & 1 & 2.5 & 1 & 2.5 \\
\hline Normal & 38 & 95 & 31 & 77.5 \\
\hline Total & 40 & 100 & 40 & 100 \\
\hline
\end{tabular}

$\mathrm{n}=80$.

${ }^{*} p<0.05$ is statistically significant.

Normal hearing in cases $-95.00 \%$.

Normal hearing in control group $-77.50 \%$.

Chi. Square $=6.155$.

$\mathrm{Df}=2$.

$p=0.046$ - This difference was statistically significant.

\section{Discussion}

Tympanic membrane reconstruction using a variety of grafts, inclusive of fascia temporalis, palisade cartilage, cartilage island and perichondrium have been extensively studied $[5,6,12]$. Each graft has its own downfall, for example, the utilization of temporalis fascia as graft leads in some part to residual perforation owing to its property of poor dimensional stability, which can lead to perforation [13]. Comparing cartilage as a graft, it was found that for less severe middle ear disorders, in which the functional outcome is more essential, the use of cartilage is not recommended [14]. Various techniques like Under-lay, On-lay and Interlay have been described in the literature for tympanoplasty.

Although the type of graft used can affect the outcome of a tympanoplasty procedure, the technique of tympanoplasty implemented has been demonstrated to have no impact to its success/failure $[5,6,13]$. This corroborates the assertion that there is a need and advantage of using an adhesive/glue to aid the success rate of a tympanoplasty. Reduction in the graft displacement as a cause of failure of tympanoplasty is the major advantage of using the sealant. The versatility of this substance in the repair of tissues has been tremendous since its invention. Matras and colleagues successfully used a highly concentrated fibrinogen solution in combination with factor XIII, thrombin, and calcium chloride to seal severed nerves in animal experiments.
A few years later, Matras and Kuderna reported on the application of this new method in humans [15]. In composition FS is made up of fibrinogen (lyophilized pooled human concentrate) and thrombin (human, which is reconstituted with calcium chloride), which is then mixed together and applied to tissue sites to glue them together. It is the only agent presently approved as a hemostat, sealant, and adhesive by the Food and Drug Administration (FDA) [16]. Added advantages include that it comes with an application device making it easy to use and that it works on various types of grafts like conjunctival-limbal autographs [17] and periodontal flaps [18]

The technique though simple is still unique, as it has not been described before in any of the published articles. When used in our study we discovered that it just took a few minutes near the end of the surgery for the glue to settle. As the results show, it added to the success rate of the graft uptake. The hearing analysis was done at 2 months post-op, as the first three months post-op are the most important for graft observation since late graft failure is rare [19]. Hearing analysis also showed a significant difference which can be attributed to better graft uptake. Only one article has been published regarding the use of Fibrin glue in tympanomastoidectomy over the last decade [20]. This is the only study from our knowledge that has compared its efficacy with a control group.

EVICEL, the FS used in our study, is composed of two main components - Frozen solutions of BAC2 (fibrinogen) and Thrombin. It is indicated as an adjunct to hemostasis in surgeries like tympanoplasty or for that matter, any surgery where the control of bleeding by routine surgical techniques like sutures and cautery are impractical. On its application, the adhesive activates the conversion of fibrinogen into fibrin, by thrombin, thus activating the last physiological step of the coagulation system. A fibrin clot is thus formed, which acts as the sealant [21].

When compared to the other used FS- TISSEAL, the mean Young modulus and tensile strength of the fibrin clots produced by EVICEL were significantly higher than those of clots produced by TISSEEL ( $\mathrm{P}<0.05$ for both). Fibrin clots formed with EVICEL have a much higher resistance to stretching and tensile strength and are more capable of maintaining their structure against applied force than those formed with TISSEEL. EVICEL also allows more rapid development of fibrin clots. This superior clot strength and resilience obtained with EVICEL relative to TISSEEL may be due in large part to the presence of factor XIII [22].

The only drawbacks noticed during the study was the lack of availability of the FS in all hospitals. However, the distribution has greatly improved over the last 3 years. The efficacy of FS with the use of perichondrium or cartilage still needs to be studied. This method could be adopted by various ENT surgeons across the world and their results subsequently should be published. This will give us a broader perspective on the efficacy of this new technique. 


\section{Conclusion}

There is potential advantage in the usage of FS as an adjunct to routine type 1 tympanoplasty procedure to improve the success rate. It not only provides a better chance of graft uptake but also results in improved hearing outcomes, as found in our study.

\section{References}

1. Wullstein $H$ (1956) Theory and practice of tympanoplasty. The Laryngoscope 66: 1076-1093.

2. Sheehy J, Glasscock M (1967) Tympanic Membrane Grafting with Temporalis Fascia. Archives of Otolaryngology - Head and Neck Surgery 86(4): 391-402.

3. Chhapola S, Matta I (2011) Cartilage-Perichondrium: An Ideal Graft Material? Indian Journal of Otolaryngology and Head \& Neck Surgery 64(3): 208-213.

4. Pradhan P, Anant A, Venkatachalam VP (2017) Comparison of Temporalis Fascia and Full-Thickness Cartilage Palisades in Type-I Underlay Tympanoplasty for Large/Subtotal Perforations. Iranian Journal of Otorhinolaryngology 29(91): 63-68.

5. Kazikdas K, Onal K, Boyraz I, Karabulut E (2007) Palisade cartilage tympanoplasty for management of subtotal perforations: a comparison with the temporalis fascia technique. European Archives of Oto-RhinoLaryngology 264(9): 985-989.

6. Demirpehlivan I, Onal K, Arslanoglu S, Songu M, Ciger E, et al (2011) Comparison of different tympanic membrane reconstruction techniques in type I tympanoplasty. European Archives of Oto-RhinoLaryngology 268(3): 471-474.

7. Finerman WB (1964) Causes of Failure in Tympanoplasty. Journal of the National Medical Association 56(2): 136-138.

8. Prasad V, Prasad K, shenoy V, Raghavendra Rao A, Panduranga Kamath $\mathrm{M}$, et al. (2014) A study of middle ear reconstruction, the degree of functional restoration and causes of graft failure following chronic ear disease. Egyptian Journal of Ear, Nose, Throat and Allied Sciences 15(2): 103-108.

9. Babighian G (1986) Fibrin Sealant (Tissucol/Tisseel) in Ear Surgery (A 4-Year Experience). In: Schlag G, Redl H (Eds.), Fibrin Sealant in Operative Medicine. Springer, Berlin, Heidelberg.

10. Portes K, de Campos Duprat A, Lancellotti C, Silva L, de Souza F (2012) Influence of selant fibrin on the wound healing of the pig's vocal folds. Brazilian Journal of Otorhinolaryngology 78(1): 51-56.
11. Jackler R (2012) A Regenerative Method of Tympanic Membrane Repair Could Be the Greatest Advance in Otology Since the Cochlear Implant. Otology \& Neurotology 33(3): 289.

12. Mauri M, Neto J, Fuchs S (2001) Evaluation of Inlay Butterfly Cartilage Tympanoplasty: A Randomized Clinical Trial. The Laryngoscope 111(8): 1479-1485.

13. Indorewala S, Pagare R, Aboojiwala S, Barpande S (2004) Dimensional Stability of the Free Fascia Grafts: A Human Study. The Laryngoscope 114(3): 543-547.

14. Cavaliere M, Mottola G, Rondinelli M, Iemma M (2009) Tragal cartilage in tympanoplasty: anatomic and functional results in 306 cases. Acta Otorhinolaryngologica Italica 29(1): 27-32.

15. Marquet J (1985) Fibrin glue in tympanoplasty. Am J Otol 6: 28-30

16. Spotnitz W (2014) Fibrin Sealant: The Only Approved Hemostat, Sealant, and Adhesive-a Laboratory and Clinical Perspective. ISRN Surgery 2014: 1-28.

17. Monga S, Gupta A, Kekunnaya R, Goyal S, Vemuganti G, et al. (2012) Childhood Pterygium: A Descriptive Study of 19 Cases Presented to a Tertiary Eye Care Center. American Journal of Ophthalmology 154(5): 859-864.

18. Pulikkotil SJ, Nath S (2013) Fibrin sealant as an alternative for sutures in periodontal surgery. Journal of the College of Physicians and Surgeons-Pakistan 23(2): 164-165.

19. Singh G, Sidhu T, Sharma A, Singh N (2005) Tympanoplasty type I in children - an evaluative study. International Journal of Pediatric Otorhinolaryngology 69(8): 1071-1076.

20. Kobayashi T, Gyo K, Komori M, Hyodo M (2017) Polyglycolic acid sheet attached with fibrin glue can facilitate faster epithelialization of the mastoid cavity after canal wall-down tympanoplasty. Auris Nasus Larynx 44(6): 685-689.

21. Dhillon $S$ (2011) Fibrin Sealant (Evicel ${ }^{\circledR}\left[\right.$ Quixil $® /$ Crosseal $\left.{ }^{T M}\right]$ ). Drugs 71(14): 1893-1915.

22. Hickerson W, Nur I, Meidler R (2011) A comparison of the mechanical, kinetic, and biochemical properties of fibrin clots formed with two different fibrin sealants. Blood Coagulation \& Fibrinolysis 22(1): 1923.

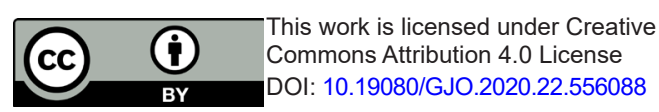

\section{Your next submission with Juniper Publishers will reach you the below assets}

- Quality Editorial service

- Swift Peer Review

- Reprints availability

- E-prints Service

- Manuscript Podcast for convenient understanding

- Global attainment for your research

- Manuscript accessibility in different formats

( Pdf, E-pub, Full Text, Audio)

- Unceasing customer service

Track the below URL for one-step submission https://juniperpublishers.com/online-submission.php 